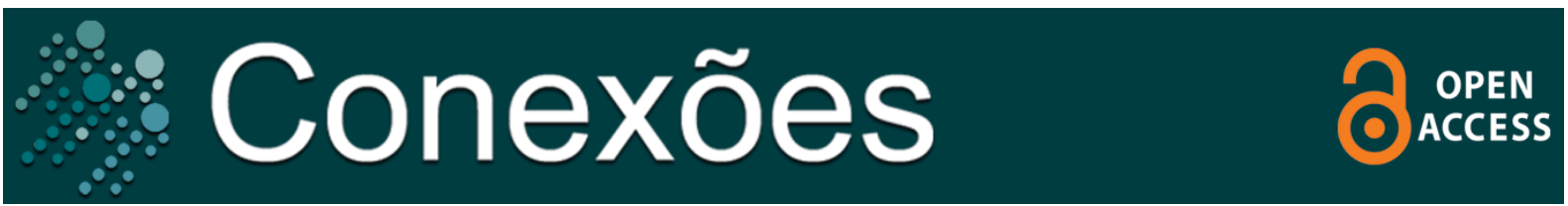

Apresentação

\title{
Educação Física, corpo e linguagem
}

\author{
Physical Education, body and language
}

Educación Física, cuerpo, lenguaje

Felipe Quintão de Almeida ${ }^{1}$

Alberto Moreno-Doña ${ }^{2}$

\section{RESUMO}

Trata-se de um dossiê cujo objetivo é discutir a relação entre a $E F$, o corpo e a linguagem. Reúne artigos escritos por colegas da Espanha, do Chile e do Brasil. Analisa a temática desde perspectivas teóricas e metodológicas diversas, todas elas empenhadas em garantir centralidade ao corpo no processo de elaboração do conhecimento e na própria linguagem.

Palavras-chave: Educação Física. Linguagem. Corpo.

${ }^{1}$ Universidade Federal do Espírito Santo, Centro de Educação Física e Desportos. Departamento de Ginástica, Laboratório de Estudos em Educação Física, Vitória - ES, Brasil.

2 Universidad de Valparaíso, Facultad de Medicina, Escuela de Educación Parvularia, Viña del Mar, Región de Valparaíso, Chile.

\section{Correspondência:}

Centro de Educação Física e Desportos, Avenida Fernando Ferrari, 514, Goiabeiras, Vitória - ES, CEP 29075-910. Email: fqalmeida@hotmail.com 


\section{ABSTRACT}

This special issue discusses the relation between Physical Education, body and language. It embraces papers by researchers from Spain, Chile and Brazil, which analyze this theme from different theoretical and methodological approaches, all of them interested in underlining the main role of the body on the processes of making of knowledge and language.

Keywords: Physical Education. Language. Body.

\section{RESUMEN}

Se trata de un dosier cuyo objetivo es discutir la relación entre la Educación Física, el cuerpo y el lenguaje. Reúne artículos escritos por colegas de España, Chile y Brasil. Analiza la temática desde perspectivas teóricas y metodológicas diversas, todas ellas dedicadas a garantizar centralidad al cuerpo en el proceso de elaboración del conocimiento y en el propio lenguaje.

Palabras Clave: Educación Física. Lenguaje. Cuerpo. 


\section{Apresentação}

No início dos anos 1970, mais precisamente no Decreto-lei 69.450/71, estabeleceu-se, no plano legal, que a Educação Física seria uma atividade escolar responsável por aprimorar forças físicas, morais, cívicas, psíquicas e sociais do educando. Essa compreensão, já a partir daquele momento, foi criticada desde diferentes perspectivas, o que levou, nas décadas seguintes, a uma alteração na "paisagem cognitiva" da disciplina, que teria transitado da sua compreensão como uma mera atividade para a ideia de que o conhecimento mobilizado nas suas aulas constituía uma forma de linguagem que se materializava em um saber-fazer, em um discurso sobre e, além disso, em um saber relacionar-se.

Umas das consequências do novo universo simbólico de legitimação lentamente elaborado a partir de então foi a admissão da Educação Física escolar como um componente curricular da área de "linguagens". No âmbito legislativo, desde pelo menos a publicação da Lei de Diretrizes e Bases da Educação Nacional, de 1996, passando pelos Parâmetros Curriculares Nacionais (1997), pelas Diretrizes Curriculares Nacionais para o Ensino Fundamental (2010) e para o Ensino Médio (2012), até a recente divulgação da Base Nacional Comum Curricular (2017), consolidou-se a ideia de que a Educação Física compunha aquela área, cuja finalidade seria possibilitar

[...] aos estudantes participar de práticas de linguagem diversificadas, que Ihes permitam ampliar suas capacidades expressivas em manifestações artísticas, corporais e linguísticas, como também seus conhecimentos sobre essas linguagens (BNCC, 2017, p. 63).

Reconheceu-se, ainda, o estatuto de "linguagem" do corpo, que passou a ser considerado como "objeto" de conhecimento escolar. Nesse contexto, e ainda segundo a BNCC (2017), a Educação Física passou a ser entendida como a disciplina que lidaria com os saberes corporais, mas também com experiências estéticas, lúdicas e emotivas que se inscreviam no âmbito da racionalidade discursiva, mas que não se restringiam a ela. Experimentar e refletir criticamente sobre tais saberes e experiências passou a ser uma das potencialidades da Educação Física, com repercussões diversas na formação de professores, nos currículos escolares, na prática profissional, etc.

Neste dossiê, os autores foram incitados a discutir, desde diferentes "lugares", essa inédita condição da Educação Física, mas também o novo status ontológico e epistemológico do corpo em sua imanente capacidade de produzir nos sujeitos experiências que estão aquém (mas também compõem com elas) da linguagem verbal e/ou da racionalidade científica. Sua intenção, todavia, não foi apenas evidenciar as "aberturas" produzidas pelas novas compreensões em curso, mas, de igual maneira, refletir sobre os alcances dessas diferentes linguagens ao "dizerem", também por meio da Educação Física, alguma coisa "sobre o mundo". 
Oito artigos compõem esta edição especial da revista Conexões. No primeiro deles, Rodrigo Castillo Cuadra e Alberto Moreno Doña advogam, à luz da realidade chilena, em favor de um quehacer pedagógico baseado no conhecimento encarnado, o que possibilitaria pensar processos educativos, também na Educação Física, "incorporados" que revelam, por assim dizer, uma "antecipação" do corpo à própria linguagem. Felipe Quintão de Almeida oferece uma análise do conceito de "educación corporal", oportunidade para discutir a relação entre corpo e linguagem nos escritos de um colega argentino (Ricardo Crisorio) e de outro, uruguaio (Raumar Rodríguez Giménez). Sem perder de vista a necessidade de corporificar as aprendizagens, Enrique Rivera, Carmen Trigueiros Cervantes e Francisco Javier Giles Girela, desde o contexto espanhol, apresentam a experiência de uma "tertúlia dialógica corporal" que objetiva ensinar estudantes de Educação Física nas escolas a construir sua corporeidade com o "outro" desde uma perspectiva social. Mauro Betti oferece uma oportunidade para leitores e leitoras aprenderem mais sobre a abordagem da linguagem oferecida pela semiótica de Charles Sanders Pierce e suas possíveis implicações para a Educação Física escolar. Terezinha Petrúcia da Nóbrega, desde a filosofia de Merleau-Ponty, afirma o lugar do corpo na linguagem e na expressão por meio do corpo estesiológico, da intercorporeidade e do logos estético. Paulo Evaldo Fensterseifer e Maria Regina Johann, desde uma perspectiva crítica-hermenêutica, discutem a necessidade de uma compreensão mais abrangente da linguagem, condição para que um saber ético-estético, expressivo e reflexivo oriente a formação, também na Educação Física. Aline Gomes Machado e Tadeu João Ribeiro Baptista descrevem, de um lado, concepções de linguagem em autores soviéticos (como Luria, Vigotsky, Bakhtin e Leontiev) e, de outro, discorrem sobre a relação entre o corpo e a linguagem no âmbito de perspectivas diversas do campo da Educação Física. Encerra o dossiê o texto de Tamiris Lima Patrício e Michele Viviene Carbinatto, que relatam, a luz de Merleau-Ponty, suas experiências no universo da "Ginástica Para Todos", oportunidade para defenderem, na modalidade, uma educação corporal em favor de um fazer esportivo sensível.

Desejamos a todos e a todas uma excelente leitura, na expectativa de aprendermos um pouco mais sobre o que pode o corpo, em sua relação com a linguagem, na Educação Física.

\section{REFERÊNCIAS}

BRASIL. Decreto no 69.450, de 1 de novembro de 1971. Brasília, 1971. Disponível em: https://presrepublica.jusbrasil.com.br/legislacao/115100/decreto-69450-71. Acesso em: 10 maio 2021.

BRASIL. Lei 9.394/96, de 20 de dezembro de 1996. Brasília, 1996. Disponível em: http://portal.mec.gov.br/seesp/arquivos/pdf/lei9394 Idbn1.pdf. Acesso em: 10 maio 2021.

BRASIL. Ministério da Educação. Base Nacional Comum Curricular. Brasília, 2017. Disponível em: http://basenacionalcomum.mec.gov.br/. Acesso em: 10 maio 2021. 
BRASIL. Parâmetros curriculares Nacionais. Brasília: Ministério da Educação, 1997. Disponível em: http://portal.mec.gov.br/seb/arquivos/pdf/livro01.pdf. Acesso em: 10 maio 2021.

BRASIL. Resolução no 2, de 30 de janeiro de 2012. Define Diretrizes Curriculares Nacionais para o Ensino Médio. Diário Oficial da República Federativa do Brasil, Brasília: Ministério da Educação; Conselho Nacional de Educação; Câmara de Educação Básica, 2012. Disponível em:

http://portal.mec.gov.br/index.php?option=com docman\&view=download\&alias=9864rceb002-12\&category slug=janeiro-2012-pdf\&Itemid=30192. Acesso em: 10 maio 2021.

BRASIL. Resolução no 7, de 14 de dezembro de 2010. Fixa Diretrizes Curriculares Nacionais para o Ensino Fundamental de 9 (nove) anos. 2010a. Disponível em: http://portal.mec.gov.br/dmdocuments/rceb007 10.pdf. Acesso em: 10 maio 2021.

A revista Conexões utiliza a Licença Internacional Creative Commons Atribuição 4.0, preservando assim, a integridade dos artigos em ambiente de acesso aberto.

A Revista Conexões é integrante do Portal de Periódicos Eletrônicos da Unicamp e associado/membro das seguintes instituições:
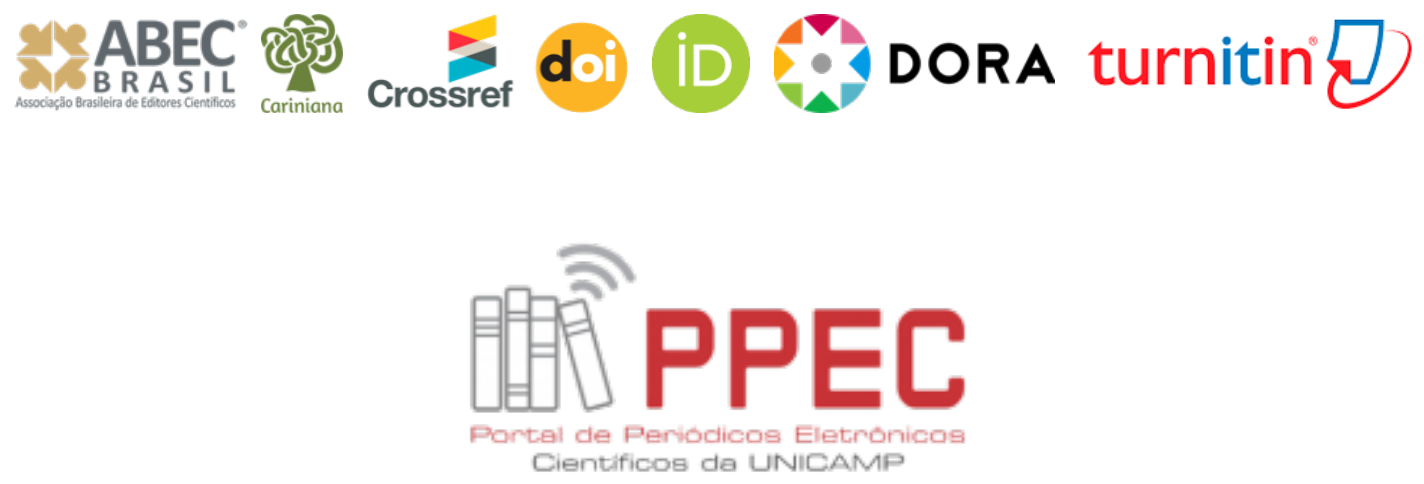